\title{
Abastecimento de água em comunidades ribeirinhas da Amazônia brasileira e promoção da saúde: análise de modelo de intervenção e de gestão
}

\section{Water supply in riverside communities in Brazilian Amazon: analyses of intervention and management models}

Cezarina Maria Nobre Souza - Doutora em Saúde Pública pela ENSP/FIOCRUZ (2007); professora e pesquisadora do Instituto Federal do Pará (IFPA). E-mail: cezarina.souza@oi.com.br

Aline Santana Nogueira - Tecnóloga em Saneamento Ambiental, formada pelo Instituto Federal de Educação, Ciência e Tecnologia do Pará (IFPA) em 2010. E-mail: aline.nogueira21@hotmail.com

Ana Samille da Silva Vasconcelos - Tecnóloga em Saneamento Ambiental, formada pelo Instituto Federal de Educação, Ciência e Tecnologia do Pará (IFPA) em 2010. E-mail: samille_vasconcelos@, yahoo.com.br

Auriana de Sousa Silva - Tecnóloga em Saneamento Ambiental, formada pelo Instituto Federal de Educação, Ciência e Tecnologia do Pará (IFPA) em 2011. E-mail: aurianasilva@hotmail.com

\section{Resumo}

Apresenta-se a avaliação de um projeto de abastecimento de água implantado em comunidades ribeirinhas de Belém, Pará, na Amazônia brasileira. Busca-se avaliar o modelo de planejamento, implantação e gestão do projeto, na perspectiva de um saneamento alicerçado na Promoção da Saúde, bem como discutir, no que tange ao acesso à água potável, o contexto em que vivem os ribeirinhos locais. Foram entrevistados 13 usuários e 5 idealizadores/executores do projeto, tendose identificado que todo o processo de planejamento, implantação e gestão do projeto foi marcado por ações que se associaram à prática de um saneamento voltado apenas para a prevenção de doenças, ainda distante das proposições da Promoção da Saúde.

\section{Palavras-chave}

Saneamento Básico. Abastecimento de água. Promoção da Saúde. População Ribeirinha. Amazônia. Belém.

\begin{abstract}
The purpose of this paper is to present an evaluation about a water supply project that was carried out in riverside communities of Belém, Pará, Brazilian Amazon, where there is not potable water. It aimed to evaluate the intervention and management models of the project according a basic sanitation proposal based on Health Promotion. In addition, the objective is to discuss about the water potable access by the local riverside communities. It was interviewed 13 project users and 5 project managers. The results showed that the project was related to a basic sanitation concept that aims just diseases prevention, so far from Heath Promotion ideas.
\end{abstract}

\section{Keywords}

Basic sanitation. Water supply. Health Promotion. Riverside population. Amazon. Belém. 


\section{INTRODUÇÃO}

Silva (2006), em seu estudo sobre a saúde humana e a Amazônia no século XXI, traça um retrato das condições de saneamento então vigentes, destacando as grandes disparidades existentes em termos de acesso aos serviços básicos de infraestrutura, como o abastecimento de água tratada nas áreas urbanas e rurais da região.

Indicando que esse retrato se mantém inalterado, a Pesquisa Nacional de Saneamento Básico, realizada em 2008, pelo Instituto Brasileiro de Geografia e Estatística (IBGE, 2010a), revelou que a região amazônica brasileira permanece apresentando o maior déficit nacional em termos de abastecimento de água. A pesquisa revela que $54,7 \%$ dos domicílios amazônicos não têm acesso à rede geral e que apenas $10,5 \%$ dos municípios da região possuem formas alternativas de abastecimento. Além disso, segundo a mesma fonte, dentre os municípios que em 2008 distribuíam água sem qualquer tipo de tratamento, 20,8\% estão situados na região, com destaque para os estados do Pará (40\% dos municípios) e Amazonas (38,7\% dos municípios).

Manaus, no Amazonas, com 1.802.525 habitantes; e Belém, no Pará, com 1.392.031 habitantes (IBGE, 2010b), são as duas maiores capitais amazônicas e, em termos de cobertura dos serviços de abastecimento de água, alcançam percentuais de $91,23 \%$ e $81,61 \%$, respectivamente(SNIS, 2011), ainda requerendo esforços para atingir a universalização do atendimento.

Em Belém, a maior parte da região insular, composta por 39 ilhas, não dispõe desse serviço. Alternativas tecnológicas para a resolução do problema têm sido propostas e implementadas, inclusive por iniciativa de entidades não governamentais. Nesse contexto, este trabalho, como parte de um estudo de maior envergadura, apresenta a avaliação de um projeto implantado em três dessas ilhas, a partir do ideário da Promoção da Saúde (SOUZA; FREITAS; MORAES, 2007; SOUZA; FREITAS, 2008; SOUZA; FREITAS, 2009; SOUZA; FREITAS, 2010).

Seu foco está voltado para a gestão do projeto implantado - aspecto este que pode tanto potencializar quanto restringir os impactos positivos de uma intervenção em saneamento (HELLER; NASCIMENTO, 2005). Parte-se da hipótese de que projetos de saneamento implementados em localidades com características marcantemente diversas das áreas urbanas, como é o caso em estudo, requerem modelos de implantação e gestão alicerçados em uma concepção de saneamento que extrapole a visão estritamente voltada para a prevenção de doenças. Assim, busca-se investigar se o projeto em análise se aproxima de uma visão preventivista - e hegemônica - de saneamento (SOUZA; FREITAS, 2009) ou se, em alguma medida, aproxima-se de uma concepção mais ampliada, voltada para a promoção da saúde.

Novos Cadernos NAEA • v. 15 n. 2 • p. 343-360 • dez. 2012 
Além disso, busca-se também destacar, no que tange ao acesso à água potável, o contexto em que vivem ribeirinhos habitantes da maior bacia hidrográfica do Brasil, dentro da Região Metropolitana de Belém (RMB), num flagrante contraste entre a abundância e a escassez de água. Neste sentido, merece ser enfatizado que o presente estudo vai ao encontro de dois aspectos evidenciados por Silva (2006) como importantes na Amazônia: o déficit de água potável e a carência de estudos sobre a população ribeirinha.

Nas seções seguintes são apresentados o projeto em análise, o perfil da população local, o referencial teórico que fundamentou a análise, os métodos analíticos empregados, os dados obtidos e sua discussão e as considerações finais.

\section{O PROJETO “ÁGUA EM CASA, LIMPA E SAUDÁVEL”}

Fazem parte da região insular de Belém as ilhas Nova, Jutuba e Urubuoca, nas quais foi implantado pela Cáritas de Belém - uma instituição ligada à Igreja Católica - o projeto “Água em Casa, Limpa e Saudável”, cujo objetivo foi disponibilizar água potável para a população local, por meio de um sistema de captação e tratamento de água de chuva, considerando a indisponibilidade dos recursos hídricos superficiais (decorrente do lançamento in natura de esgotos provenientes do continente) e subterrâneos (pela inconsistência do solo).

A água é captada por meio de uma calha instalada no telhado de cada casa e armazenada em reservatório de fibra de vidro, com capacidade para mil litros (Figura 1). Por meio de torneira existente no reservatório, a água é envasada em garrafas plásticas do tipo PET pintadas de preto, à meia cana. A seguir, essas garrafas são expostas ao sol por seis horas consecutivas (Figura 2), com o objetivo de eliminar os organismos patogênicos existentes (Sistema SODIS - Solar Water Disinfection).

Figura 1: Calha instalada no telhado da casa conectada ao reservatório.

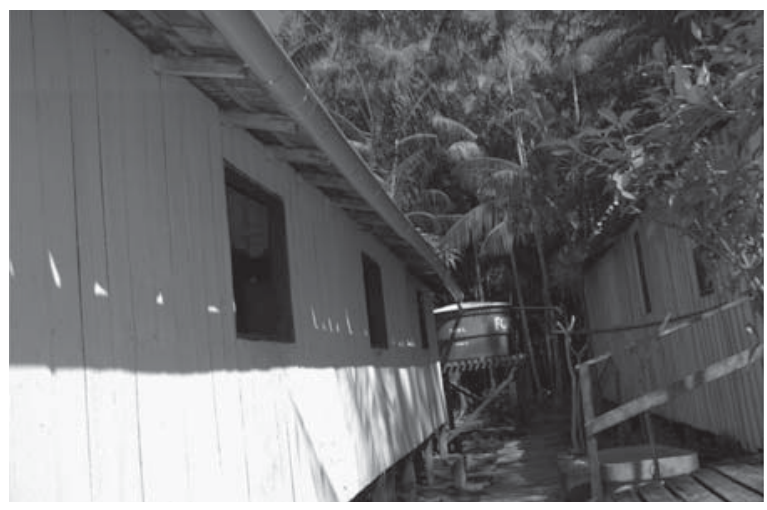

Fonte: Cáritas de Belém (2007). 
Figura 2: Garrafas plásticas contendo água expostas ao sol.

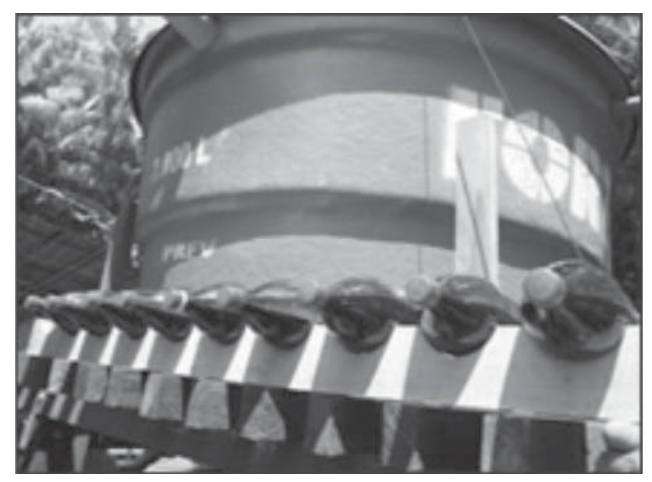

Fonte: SEDURB (2007).

\section{O PERFIL DAS ILHAS}

O perfil demográfico, habitacional, educacional, socioeconômico, epidemiológico e de saneamento encontrado nas ilhas está resumido na Tabela 1 (DUARTE; SILVA, 2011).

Tabela 1: Principais indicadores das ilhas Jutuba, Nova e Urubuoca.

\begin{tabular}{l|l|l|l}
\hline & Jutuba & Nova & Urubuoca \\
\hline População (habitantes) & 182 & 45 & 136 \\
\hline Gênero predominante & $\begin{array}{l}\text { masculino } \\
(58 \%)\end{array}$ & $\begin{array}{l}\text { masculino } \\
(55 \%)\end{array}$ & $\begin{array}{l}\text { feminino } \\
(60 \%)\end{array}$ \\
\hline $\begin{array}{l}\text { Faixas etárias predominantes } \\
\text { por sexo* (anos) }\end{array}$ & $\begin{array}{l}15 \text { a 36 (homens) } \\
5 \text { a 36 (mulheres) }\end{array}$ & $\begin{array}{l}5 \text { a } 25 \text { (homens) } \\
15 \text { a 36 (mulheres) }\end{array}$ & $\begin{array}{l}5 \text { a 10 e 15 a 25 (homens) } \\
1 \text { a 4 e 15 a 25 (mulheres) }\end{array}$ \\
\hline $\begin{array}{l}\text { Ocupação predominante por } \\
\text { sexo }\end{array}$ & $\begin{array}{l}\text { dona de casa }(46 \%) \\
\text { pescador } \\
(78 \%)\end{array}$ & $\begin{array}{l}\text { pescadora } \\
(46 \%) \\
\text { pescador } \\
(80 \%)\end{array}$ & $\begin{array}{l}\text { pescadora } \\
(32 \%) \\
\text { pescador } \\
(76 \%)\end{array}$ \\
\hline $\begin{array}{l}\text { Faixa de renda familiar } \\
\text { predominante (salário mínimo) }\end{array}$ & $\begin{array}{l}\text { menos de 1 } \\
(62 \%)\end{array}$ & $\begin{array}{l}2 \text { a 3 } \\
(38 \%)\end{array}$ & $\begin{array}{l}1 \text { a 2 } \\
(72 \%)\end{array}$ \\
\hline $\begin{array}{l}\text { Tempo médio de residência no } \\
\text { domicílio (anos) }\end{array}$ & 25,75 & $\begin{array}{l}29,11 \\
24,68\end{array}$ \\
\hline $\begin{array}{l}\text { Nível de escolaridade predo- } \\
\text { minante }\end{array}$ & Fundamental (77\%) & $\begin{array}{l}\text { Fundamental } \\
(79 \%)\end{array}$ & $\begin{array}{l}\text { Fundamental } \\
(82 \%)\end{array}$ \\
\hline Agravos prevalentes ** & Hipertensão arterial & Hipertensão arterial & Hipertensão arterial \\
\hline $\begin{array}{l}\text { Destinação dos dejetos } \\
\text { Fossa negra }\end{array}$ & $\begin{array}{l}\text { Fossa negra } \\
(100 \%)\end{array}$ & $\begin{array}{l}\text { Fossa negra (81\%) } \\
(58 \%)\end{array}$ & $\begin{array}{l}\text { Queima } \\
(100 \%)\end{array}$ \\
\hline $\begin{array}{l}\text { Destinação do lixo } \\
(81 \%)\end{array}$ & $91 \%)$ \\
\hline
\end{tabular}

* Percentuais correlatos não informados na fonte de consulta

** Percentual agregado para as três ilhas : 5\%

Fonte: Duarte e Silva (2011). 
Há na literatura científica brasileira (SOUZA, 2007; SOUZA; FREITAS; MORAES, 2007; SOUZA; FREITAS, 2008; SOUZA; FREITAS, 2009; SOUZA; FREITAS, 2010), a proposição de uma concepção de saneamento básico calcada nas ideias da Promoção da Saúde, que partiu de um conceito de Promoção tal como o descreve a Carta de Ottawa (documento resultante da I Conferência Internacional de Promoção da Saúde, realizada no Canadá em 1986): processo de capacitação da comunidade para atuar na melhoria de sua qualidade de vida e saúde (CARTA DE OTTAWA, 2005).

Esse conceito de Promoção se insere no grupo de conceitos mais amplos, que enfatizam a responsabilidade e os direitos dos indivíduos e da comunidade pela sua própria saúde, incluindo maior participação no controle desse processo (BUSS, 2003). Ao mesmo tempo, tal conceito se associa à corrente da Nova Promoção da Saúde, distanciando-se da corrente behaviorista, para a qual a promoção consiste em trabalhar unicamente pela transformação dos comportamentos e estilos de vida dos indivíduos (CARVALHO, 2005). Pode-se dizer, então, que o conceito e as práticas de saneamento básico propostos no Brasil estão associados à Nova Promoção da Saúde.

A referida proposição (SOUZA; FREITAS; MORAES, 2007; SOUZA; FREITAS, 2008; SOUZA; FREITAS, 2009; SOUZA; FREITAS, 2010) também busca, por meio de 10 categorias analíticas, estabelecer diferenças entre um saneamento lastreado na Promoção e um saneamento voltado para a prevenção de doenças, sob a inspiração de trabalhos de outros autores (BUSS, 2003; STATCHENKO; JENICECK, 1990). As categorias foram: conceito de saneamento; conceito de ambiente; conceito de saúde; objetivos dos projetos; preocupação quanto à sustentabilidade das ações; articulação entre políticas, instituições e ações; modelo de intervenção; estratégias; executores dos projetos; modelo de gestão.

O saneamento seria, então, sob o enfoque da Promoção, uma intervenção multidimensional que se dá no ambiente, considerado em suas dimensões física, social, econômica, política e cultural, com vistas a impactar positivamente a saúde, também como uma multidimensionalidade. Seria composto pelos sistemas de engenharia (como o de abastecimento e tratamento de água), pelas ações de educação sanitária e ambiental, pelo arcabouço institucional e legal (SOUZA; FREITAS; MORAES, 2007).

Quanto aos objetivos dos projetos, estes estariam voltados para a melhoria da qualidade de vida e erradicação das doenças, combatendo as suas 
causas e determinantes, por meio da implantação desses sistemas de engenharia, em parceria com um conjunto de ações complementares, ligadas aos outros determinantes da saúde, como habitação, emprego, alimentação e educação (SOUZA; FREITAS; MORAES, 2007).

Sua preocupação quanto à sustentabilidade das ações ao longo do tempo estaria voltada a assegurar que os objetivos supracitados fossem alcançados amplamente. Para tanto, buscaria realizar a adequação das tecnologias ao contexto em que são empregadas, inclusive levando em conta as características culturais da população-alvo (SOUZA; FREITAS; MORAES, 2007).

Visaria à articulação entre políticas e ações, assim como entre os setores técnicos e a população, objetivando o fortalecimento da mesma e o compartilhamento de responsabilidades, inclusive na tomada de decisões. Isto asseguraria à população-alvo exercer a efetiva participação em todo o processo, desde a fase de planejamento da intervenção (SOUZA; FREITAS; MORAES, 2007).

Nessa perspectiva, o saneamento estaria voltado a contribuir para a promoção do ser humano. Para isso, a educação ambiental seria entendida como uma estratégia fundamentada em abordagens simples e capazes de proporcionar o empoderamento, ou seja, a aquisição de poder técnico e de consciência política por parte de indivíduos e comunidades, para atuarem em prol de sua saúde, com base no fortalecimento dos recursos humanos e materiais disponíveis (CARVALHO, 2005).

Por outro lado, o saneamento, do ponto de vista da prevenção de doenças (SOUZA; FREITAS; MORAES, 2007), partiria da concepção de prevenção como ação capaz de: 1) impedir ou reduzir a ocorrência de uma doença ou agravo à saúde de um indivíduo; 2) interromper ou retardar o progresso de uma doença; 3) reduzir a incapacidade residual resultante do adoecimento.

Nessa perspectiva, o saneamento seria uma intervenção de engenharia realizada no ambiente físico, com o fim de impedir a disseminação das doenças pela interrupção ou comprometimento do ciclo vital de seus agentes causais, garantindo a salubridade ambiental (SOUZA; FREITAS; MORAES, 2007).

Como prevenção de doenças, o saneamento entenderia a saúde como ausência de doenças e o ambiente como o espaço físico, criando meios para impedir a transmissão de doenças e assegurando a salubridade ambiental (SOUZA; FREITAS; MORAES, 2007).

Assim, o saneamento preocupar-se-ia com a articulação apenas entre setores técnicos, para que os sistemas de engenharia pudessem operar ao longo do tempo, e desenvolveria adaptações tecnológicas às características físicas da 
área-alvo da intervenção (SOUZA; FREITAS; MORAES, 2007). Concentraria a responsabilidade pelas ações e tomadas de decisão exclusivamente nas mãos dos engenheiros e de sua equipe de educação ambiental. Nesse sentido, consideraria a educação ambiental como atividade de fundamental importância para ensinar novos hábitos e costumes à população, cuja participação na intervenção se daria apenas por meio de sua adesão ao que previamente já estaria decidido pelos engenheiros (SOUZA; FREITAS; MORAES, 2007).

De modo a sistematizar os conceitos propostos apresentados acima, a Tabela 2 evidencia de forma didática as diferenças práticas existentes entre um saneamento segundo a Promoção da Saúde e um saneamento que objetiva apenas a prevenção de doenças.

Tabela 2: Diferenças práticas entre o saneamento na perspectiva da Promoção da Saúde e o saneamento na compreensão da prevenção de doenças.

\begin{tabular}{|c|c|c|}
\hline Categorias & $\begin{array}{l}\text { Saneamento como Promoção } \\
\text { da Saúde }\end{array}$ & $\begin{array}{c}\text { Saneamento como } \\
\text { Prevenção de Doenças }\end{array}$ \\
\hline $\begin{array}{l}\text { Objetivos dos } \\
\text { projetos }\end{array}$ & $\begin{array}{l}\text { Implantação de sistemas, com vistas a } \\
\text { contribuir para mudanças na situação } \\
\text { dos indivíduos e de seu ambiente, e com } \\
\text { isso erradicar a doença, melhorando a } \\
\text { performance de indicadores sociais, de } \\
\text { saúde e ambientais, ou seja, a qualidade } \\
\text { de vida. }\end{array}$ & $\begin{array}{l}\text { Implantação de sistemas, com } \\
\text { vistas a obstaculizar a interação } \\
\text { agente-suscetível, e com isso } \\
\text { impedir a manifestação da do- } \\
\text { ença, melhorando a performan- } \\
\text { ce de indicadores epidemiológi- } \\
\text { cos e ambientais. }\end{array}$ \\
\hline $\begin{array}{l}\text { Preocupação } \\
\text { quanto à } \\
\text { sustentabilidade } \\
\text { das ações }\end{array}$ & $\begin{array}{l}\text { Sustentabilidade dos sistemas para al- } \\
\text { cançar os objetivos dos projetos con- } \\
\text { forme descrito acima. }\end{array}$ & $\begin{array}{l}\text { Sustentabilidade dos sistemas } \\
\text { para alcançar os objetivos dos } \\
\text { projetos conforme descrito } \\
\text { acima. }\end{array}$ \\
\hline $\begin{array}{l}\text { Articulação } \\
\text { entre políticas, } \\
\text { instituições e ações }\end{array}$ & $\begin{array}{l}\text { Articulação institucional e interinstitu- } \\
\text { cional para empoderamento. }\end{array}$ & $\begin{array}{l}\text { Articulação institucional e inte- } \\
\text { rinstitucional para implantação } \\
\text { de sistemas. }\end{array}$ \\
\hline $\begin{array}{l}\text { Modelo de } \\
\text { intervenção }\end{array}$ & $\begin{array}{l}\text { Participativo, adaptativo, intersetorial } \\
\text { (entre técnicos e população). }\end{array}$ & $\begin{array}{l}\text { Adaptativo, tecnicista, interse- } \\
\text { torial (entre setores técnicos). }\end{array}$ \\
\hline Estratégias & $\begin{array}{l}\text { Educação sanitária e ambiental voltada } \\
\text { para o empoderamento. Negociação } \\
\text { entre todos os atores envolvidos. }\end{array}$ & $\begin{array}{l}\text { Educação sanitária e ambien- } \\
\text { tal voltada para ensinar novos } \\
\text { hábitos e costumes. Convenci- } \\
\text { mento da população-alvo. }\end{array}$ \\
\hline $\begin{array}{l}\text { Executores dos } \\
\text { projetos }\end{array}$ & $\begin{array}{l}\text { Órgão responsável compartilhando } \\
\text { com outros órgãos oficiais e organiza- } \\
\text { ções da sociedade. }\end{array}$ & $\begin{array}{l}\text { Órgão responsável (engenhei- } \\
\text { ros e sua equipe de educação } \\
\text { ambiental). }\end{array}$ \\
\hline Modelo de gestão & $\begin{array}{l}\text { Participativo, intersetorial, contextuali- } \\
\text { zado, adaptativo, inclusivo. }\end{array}$ & $\begin{array}{l}\text { Impositivo, tecnicista, adaptati- } \\
\text { vo (em termos técnicos). }\end{array}$ \\
\hline
\end{tabular}

Fonte: Souza, Freitas e Moraes (2007). 


\section{O TRABALHO DE CAMPO}

Numa abordagem qualitativa, buscando identificar a visão êmica (de dentro do grupo) dos usuários e dos voluntários da Cáritas de Belém que atuaram como idealizadores/executores do projeto em estudo, no período de dezembro de 2008 a agosto de 2009, foram realizadas entrevistas gravadas em áudio, com uma amostra composta por esses sujeitos.

Tal amostra teve seu tamanho definido levando-se em conta a busca pelo aprofundamento das questões com um número reduzido de entrevistados. Assim, 15 sujeitos (cinco de cada ilha) deveriam compor a amostra de usuários e cinco deveriam integrar a amostra de idealizadores/executores. Os critérios de inclusão para usuários foram: residir nas ilhas e ter o sistema de captação e tratamento da água de chuva implantado em sua residência. Os critérios para idealizadores/ executores foram: pertencer ao quadro de voluntários da Cáritas e ter atuado na implantação dos sistemas nas ilhas.

As entrevistas foram conduzidas em meio a um diálogo informal, orientado por um roteiro específico para cada amostra de entrevistados. O corpus resultante foi analisado à luz do referencial teórico já apresentado.

\subsection{Entrevistas com usuários}

Por conta de fatores imprevistos, foram realizadas somente 13 entrevistas, sendo quatro na ilha Nova e em Jutuba e cinco em Urubuoca. Em função de sua permanência em casa durante todo o dia, diferentemente dos homens que se deslocam para atividades fora das ilhas, somente foi possível entrevistar mulheres. Estas possuem baixo grau de instrução (fundamental incompleto); são donas de casa e, juntamente com seus maridos, atuam nas atividades de agricultura, caça e pesca; são de naturalidade paraense; constituíram família ainda muito jovens, por não terem outras alternativas, vindo a se tornarem mães também muito cedo e algumas já possuem netos.

O roteiro de apoio às entrevistas contemplou perguntas adaptadas ao nível de escolaridade e entendimento das entrevistadas, e teve por objetivo revelar aspectos do planejamento, da implantação e da gestão da intervenção realizada. As perguntas foram as seguintes:

1) Como obtinha água antes do projeto para atender suas necessidades?;

2) Que tipo de tratamento realizava antes da utilização da água?;

3) Como tomou conhecimento do projeto?;

4) De quem recebeu orientação sobre a operação do sistema SODIS?; 
5) Existe alguma dificuldade na instalação ou na forma de usar o sistema SODIS?;

6) Qual sua avaliação do sistema SODIS?

\subsection{Entrevistas com idealizadores e executores}

Foram entrevistados cinco componentes do corpo técnico do projeto. Eles são voluntários da Cáritas de Belém, com formação em engenharia civil, engenharia sanitária e em outras áreas, tendo sido os responsáveis pela intervenção realizada, uma vez que, por meio de seus conhecimentos, adaptaram o projeto original do semiárido cearense (BOTTO, 2010) para a realidade local.

Para entrevistá-los, também foi empregado um roteiro de apoio, contendo as seguintes perguntas:

1) Como surgiu a ideia da realização do projeto?;

2) Porque escolheram as ilhas Nova, Jutuba e Urubuoca para implantar o projeto?;

3) Em que locais o projeto já foi implantado?;

4) Que avaliação se tem dos projetos já implantados?;

5) Quais foram as maiores dificuldades para a implantação do projeto?

\subsection{Aspectos éticos envolvidos}

Deve-se ressaltar que todos os aspectos da ética em pesquisa foram respeitados, de acordo com a legislação brasileira, assegurando-se a confidencialidade da identidade dos entrevistados e a assinatura, por parte deles e das pesquisadoras, de Termo de Consentimento Livre e Esclarecido, aprovado segundo o Parecer n 014/2008, emitido pelo Comitê de Ética em Pesquisa do Instituto Evandro Chagas.

\section{RESULTADOS OBTIDOS}

\subsection{Respostas das Usuárias}

As respostas das usuárias foram sistematizadas na Tabela 3. 
Tabela 3: Resumo das respostas obtidas entre as usuárias.

\begin{tabular}{l|l}
\hline Perguntas & Respostas obtidas \\
\hline $\begin{array}{l}\text { 1) Como obtinha água antes do projeto } \\
\text { para atender suas necessidades? }\end{array}$ & $\begin{array}{l}\text { De ilhas próximas; } \\
\text { De localidade do continente; } \\
\text { Do rio; } \\
\text { Direto da chuva. }\end{array}$ \\
\hline $\begin{array}{l}\text { 2) Que tipo de tratamento realizava antes } \\
\text { da utilização da água? }\end{array}$ & $\begin{array}{l}\text { Adicionava produtos químicos; } \\
\text { Fervia; } \\
\text { Filtrava; } \\
\text { Não fazia nada. }\end{array}$ \\
\hline $\begin{array}{l}\text { 3) Como tomou conhecimento do } \\
\text { projeto? }\end{array}$ & $\begin{array}{l}\text { Foi convidada pelo pároco local; } \\
\text { Foi convidada por professores ou pessoas } \\
\text { ligadas à Cáritas. }\end{array}$ \\
\hline $\begin{array}{l}\text { 4) De quem recebeu orientação sobre a a } \\
\text { operação do sistema? }\end{array}$ & $\begin{array}{l}\text { Do engenheiro e do padre; } \\
\text { De professores locais; } \\
\text { Do pessoal da Cáritas. }\end{array}$ \\
\hline 5) Existe alguma dificuldade na instalação & Não há dificuldade; \\
ou na forma de usar o sistema? & Os preguiçosos têm dificuldade; \\
& Dá trabalho, mas antes era pior. \\
\hline 6) Qual sua avaliação do sistema? & Os resultados são positivos. \\
\hline
\end{tabular}

Sobre a pergunta 1 (Como obtinha água antes do projeto para atender suas necessidades?), as respostas revelaram que antes do projeto, a água era obtida em ilhas próximas ou no continente; ou retirada do rio (da baía que circunda as ilhas) em determinado período do ano, quando não se apresentava salgada, já que a região sofre influência do oceano; ou ainda, obtida da chuva, coletada diretamente em um recipiente.

Pelos relatos, ficou evidenciado que a população como um todo enfrentava duas grandes dificuldades para se deslocar até as ilhas próximas e o continente: o risco de naufrágio e a carência de recursos financeiros para realizar esse deslocamento. Assim, restava-lhe apenas a alternativa de coletar água da chuva ou do rio (baía do Guajará). Neste último caso, a despeito de sua má qualidade, decorrente do lançamento in natura de expressivo volume de esgotos gerados na porção continental de Belém.

Relativamente à pergunta 2 (Que tipo de tratamento realizava antes da utilização da água?), verificou-se nas respostas que a maioria das entrevistadas realizava algum tipo de tratamento da água antes de ingeri-la: fervura, filtração ou adição de produtos químicos, como hipoclorito, água sanitária e sulfato de alumínio.

Em função da dificuldade enfrentada para a locomoção até outras localidades, a fim de obter hipoclorito, o uso da água sanitária era comum. O Novos Cadernos NAEA •v. 15 n. $2 \cdot$ p. 343-360 • dez. 2012 
sulfato de alumínio era empregado para remover substâncias responsáveis pela presença de cor na água, mas não despertava a confiança dos usuários no que diz respeito à eliminação de bactérias.

Houve relatos de duas entrevistadas que informaram utilizar a água in natura. Justificaram seu procedimento alegando a falta de conhecimento de métodos específicos de tratamento e a crença de que a água estaria própria para o consumo, uma vez que a coletavam em recipientes, diretamente da chuva.

A respeito da pergunta 3 (Como tomou conhecimento do projeto?), verificou-se que a maior parte das entrevistadas tomou conhecimento da existência do projeto por meio do pároco local, que, sabendo das dificuldades locais, por ocasião das missas concitava a população a aceitar o projeto. Houve também relatos informando que algumas usuárias teriam tomado conhecimento do projeto por pessoas influentes nas ilhas, tais como os professores, que têm contato direto com a população ou com pessoas ligadas à Cáritas de Belém.

Com a pergunta 4 (De quem recebeu orientação sobre a operação do sistema?) foi possível identificar que todas as entrevistadas receberam orientação sobre o funcionamento do sistema, fornecida por diferentes pessoas. Há relatos de que a orientação foi dada por um engenheiro e pelo padre, a partir de reuniões específicas realizadas, assim como durante as missas celebradas. Por outro lado, uma entrevistada, moradora de Jutuba, revelou que a orientação partia dos professores que trabalham nas ilhas, por terem mais afinidade com a população. Afirmou, ainda, que algumas usuárias, por não confiarem plenamente nessa orientação, buscaram informações com pessoas ligadas à Cáritas.

Referente à pergunta 5 (Existe alguma dificuldade na instalação ou na forma de usar o sistema?), identificou-se que a maior parte das usuárias entrevistadas afirma não ter nenhuma dificuldade em usar o sistema.

Devido à falta de hábito em realizar todo o procedimento requerido (manter os telhados e calhas limpos retirando folhas, galhos e dejetos de aves, manter as garrafas plásticas limpas e trocá-las periodicamente, dentre outros), algumas entrevistadas afirmaram que só há dificuldade para aqueles que "têm preguiça". Outras reconheceram que a operação é trabalhosa, mas que antes do projeto o trabalho era maior (buscar água em outras localidades).

De acordo com a pergunta 6 (Qual sua avaliação do sistema?), foi possível identificar que todas as entrevistadas consideram-se satisfeitas com a implantação do sistema pelo projeto. 


\subsection{Respostas dos idealizadores/executores}

As respostas dos idealizadores/executores foram sistematizadas na Tabela 4.

Tabela 4. Resumo das respostas obtidas entre idealizadores/executores.

\begin{tabular}{l|l}
\hline Perguntas & Respostas obtidas \\
\hline $\begin{array}{l}\text { 1) Como surgiu a ideia da realização do } \\
\text { projeto? }\end{array}$ & $\begin{array}{l}\text { A partir de visitas às ilhas, identificando } \\
\text { a carência de água potável e o risco de } \\
\text { naufrágio. }\end{array}$ \\
\hline $\begin{array}{l}\text { 2) Por que escolheram as ilhas Nova, } \\
\begin{array}{l}\text { Jutuba e Urubuoca para implantar o } \\
\text { projeto? }\end{array}\end{array}$ & $\begin{array}{l}\text { Pela facilidade de acesso para fazer o } \\
\text { acompanhamento. }\end{array}$ \\
\hline $\begin{array}{l}\text { 3) Em que locais o projeto já foi } \\
\text { implantado? }\end{array}$ & Na região do Nordeste brasileiro. \\
\hline $\begin{array}{l}\text { 4) Que avaliação se tem dos projetos já } \\
\text { implantados em outros lugares? }\end{array}$ & Deu certo em todos os lugares. \\
\hline $\begin{array}{l}\text { 5) Quais foram as maiores dificuldades } \\
\text { para a implantação do projeto nas ilhas? }\end{array}$ & A questão financeira; \\
A aceitação pela população. \\
\hline
\end{tabular}

Com a pergunta 1 (Como surgiu a ideia da realização do projeto?), observou-se que tal ideia surgiu em 2007, a partir de visitas de autoridades religiosas às ilhas, durante as quais ficou evidente o descaso do poder público em relação à população local. Especialmente, chamou-lhes atenção a carência de água potável em plena região amazônica e o risco de morte por naufrágio a que os moradores estavam expostos quando se deslocavam, a fim de obter água em outras ilhas ou no continente.

Em relação à pergunta 2 (Por que escolheram as ilhas Nova, Jutuba e Urubuoca para implantar o projeto?), foi relatado que a escolha se deu em função de sua localização geográfica, pois são mais próximas a Belém, facilitando o acesso e, consequentemente, o acompanhamento do projeto.

A respeito da pergunta 3 (Em que locais o projeto já foi implantado?), de acordo com as respostas foi verificado que no Brasil, a região nordestina, no semiárido, foi a pioneira. Antes da implantação nas ilhas, contudo, estudos teriam sido realizados a fim de adaptar a tecnologia às condições amazônicas.

Relativamente à pergunta 4 (Que avaliação se tem dos projetos já implantados em outros lugares?), em todas as respostas foi possível identificar que os entrevistados consideram o projeto muito bem sucedido na região Nordeste do Brasil, marcada pela carência de água potável.

No que tange à pergunta 5 (Quais foram as maiores dificuldades para a implantação do projeto nas ilhas?), de acordo com os relatos dos entrevistados, 
as maiores dificuldades foram de natureza financeira, decorrentes da falta de patrocínio para transportar os materiais e equipamentos até as ilhas e realizar o monitoramento do projeto.

Foi também apontada como dificuldade a aceitação do projeto pela população. Isto porque, segundo relatou um dos entrevistados, os mesmos viviam desestimulados, em função de inúmeras promessas de resolução de seus problemas (não apenas ligados à falta de água potável) feitas por autoridades ou entidades, que, na maioria das vezes, não foram cumpridas. Levá-los a compreender que não havia nenhum interesse político ou escuso por parte da Cáritas de Belém teria exigido grande esforço.

\section{ANALISANDO OS RESULTADOS OBTIDOS}

Analisando-se os resultados a partir das categorias modelo de intervenção; estratégias; executores dos projetos e modelo de gestão, apresentadas na Tabela 2, verificase que as respostas obtidas para a pergunta 3 das usuárias e para as perguntas 1, 2 e 3 dos idealizadores/executores permitem constatar que a intervenção foi concebida em uma perspectiva que se aproxima da visão preventivista do saneamento (SOUZA; FREITAS; MORAES, 2007; SOUZA; FREITAS, 2008; SOUZA; FREITAS, 2009; SOUZA; FREITAS, 2010).

Quando as usuárias afirmam que por um lado foram convidadas a participar do projeto e, por outro, os idealizadores/executores informam que a ideia do projeto, a decisão sobre quais ilhas seriam atendidas em um primeiro momento e a definição da tecnologia empregada foram aspectos definidos pela Cáritas de Belém, pode-se considerar uma aproximação dessa forma de planejamento com um saneamento preventivista (SOUZA; FREITAS, 2009).

Isto se confirma também pelas expressões dos idealizadores/executores ao responderem as perguntas 1, 3 e 5 , quando informam ter havido adaptações às condições locais (estritamente tecnológicas); que se objetivou com isso solucionar o problema da falta de água potável enfrentado pelos moradores (objetivo centrado em si mesmo); que se buscou uma parceria intersetorial entre a Cáritas e o setor público, representado pelo Governo do Estado, para a realização da intervenção (parceria exclusiva entre setores técnicos).

No que se refere especificamente à categoria estratégias, observa-se pelas respostas que o principal recurso utilizado foi o convencimento dos moradores; primeiro para aceitarem a implantação do sistema em sua casa e depois para operá-lo corretamente. 
As respostas às perguntas 3 e 4 das usuárias revelam que todas elas foram abordadas a respeito de sua participação no projeto, seja por meio de conversas ou mesmo nas missas, assim como receberam orientação de diversas pessoas sobre como deveriam operar o sistema.

Essa forma de atuação se aproxima de uma visão preventivista do saneamento (SOUZA; FREITAS; MORAES, 2007), ao utilizar os recursos educativos dentro de uma proposta de educação ambiental e em saúde, voltada para ensinar novos hábitos e costumes à população. Ou seja, busca convencê-la a mudar seu modo de viver.

Em relação à categoria executores dos projetos, as respostas das perguntas 3 das usuárias e 2 dos idealizadores/executores também revelam a marca preventivista da intervenção: o órgão responsável (engenheiros e sua equipe de educação ambiental) assume integralmente a execução do projeto (SOUZA; FREITAS, 2009).

Respondendo à pergunta 3, as usuárias informaram terem sido convidadas a participar do projeto, enquanto que os idealizadores/executores, na pergunta 2 , reportam-se à decisão de executar o projeto. Fica claro que as moradoras foram convidadas por pessoas estranhas à comunidade, ainda que sob os auspícios de seu pároco (que também não residia no local), as quais, movidas pelas mais elevadas razões éticas e de cidadania, suprindo inclusive a lacuna que o poder público deixou ao não se fazer presente, assumiram integralmente a execução de um projeto que, segundo o esperado, teria a capacidade de alterar substancialmente o modo de vida estabelecido até então naquele lugar.

Relativamente à categoria modelo de gestão, a marca preventivista também está presente, por conta do que revelam as falas das usuárias ao responder às perguntas 3 e 4 . Isto fica evidente quando se percebe que a adesão das mesmas ao projeto parece ter sido sua única forma de participação, o que acaba por se aproximar de um saneamento preventivista (SOUZA; FREITAS; MORAES, 2007). Neste sentido, a despeito de todo um conjunto de nobres e elevadas razões, a intervenção acaba por ser impositiva, tecnicista e adaptativa apenas em termos técnicos.

Além disso, as respostas da pergunta 5 das usuárias levam a crer que existem resistências à correta operação do sistema. Há referência à "preguiça”" como um fator determinante para que algumas usuárias não realizem os procedimentos a respeito dos quais teriam recebido orientação.

As respostas obtidas na pergunta 1 das usuárias remetem também a um saneamento preventivista ${ }^{4}$, voltado para a superação das dificuldades no ambiente 
físico. Isto porque relatam a melhora do ambiente físico das ilhas e dos aspectos da saúde da comunidade, já que não é mais necessário ingerir a água do rio, assim afastando a doença.

\section{CONSIDERAÇÕES FINAIS}

Este estudo mostrou, dentro dos seus limites, que o projeto em análise associa-se a uma concepção preventivista do saneamento, levando-se em conta o referencial teórico adotado. Sobre essa constatação há dois aspectos a considerar: a associação não teve caráter proposital; dentro de seus limites o projeto tem mérito inegável.

A respeito do primeiro aspecto, a concepção preventivista do saneamento ainda é predominante no Brasil. Na literatura científica, na legislação, entre profissionais da área e entre usuários dos serviços, o saneamento é entendido essencialmente como uma ação voltada à prevenção de doenças, com todas as consequências conceituais e práticas que isso possa ter (SOUZA, 2007).

Assim, a constatação de que o projeto em análise associa-se a essa perspectiva do saneamento, pode ser considerada natural e até esperada. Não se trata, portanto, de uma associação proposital, fruto de uma escolha consciente de seus idealizadores/executores; trata-se, sim, de algo que faz parte do ideário comum.

Com relação ao segundo aspecto, mesmo incorporando os limites que uma intervenção preventivista apresenta (SOUZA; FREITAS, 2009), o projeto em estudo é relevante. Tanto do ponto de vista ético e de cidadania, quanto do técnico, deve ser expandido, considerando a necessidade de suprir a carência de água potável que constrange os ribeirinhos da região das ilhas de Belém, como também de outras regiões da Amazônia, como, por exemplo, da ilha do Marajó, também no Pará. Contudo, nesse movimento de expansão, o cuidado com as etapas de planejamento, implantação e gestão, merece ser observado dentro do enfoque de um saneamento alicerçado na Promoção da Saúde.

No contexto do projeto em análise, o êxito almejado pelos idealizadores/ executores parece ter sido, em alguma medida, empanado pela falta de participação ampla da comunidade envolvida, ao longo das etapas de planejamento e implantação, o que culminou, no dia-a-dia, com a não apropriação plena do sistema implantado, por conta da "preguiça" em realizar todo o procedimento operacional necessário, conforme referido nas entrevistas. 
Neste sentido, é importante lembrar que os programas de promoção da saúde devem ser movimentos politicamente orientados para uma perspectiva de democracia participativa, pois o modo como um problema é solucionado (democrático e participativo em oposição ao modo impositivo baseado exclusivamente no conhecimento de especialistas), é tão importante quanto a solução encontrada (WALTNER-TOWES, 2000). Se assim é numa perspectiva mais ampla, igualmente o é, em se tratando de ações de saneamento básico.

A maturidade da comunidade para assumir a responsabilidade que lhe cabe como participante efetiva de uma ação também é resultante de um processo. Neste caso, trata-se do empoderamento a que a Promoção da Saúde se refere (CARTA DE OTTAWA, 2005). Para isso, a educação para a promoção do ser humano é o motor.

\section{REFERÊNCIAS}

BOT'TO, M.P. Avaliação da viabilidade técnica e social da desinfecção solar (SODIS) em águas de cisternas de placa - estudo de caso Camurim (Itaiçaba). Disponível em: <http://www.abcmac.org.br/files/simposio/6simp_ marcio_avaliacao.pdf $>$. Acesso em: 16 jan. 2010).

BUSS, P.M. Uma introdução ao conceito de Promoção da Saúde. In: CZERESniA, D.; FreITAS, C.M. (Org.). Promoção da Saúde: conceitos, reflexões, tendências. Rio de Janeiro: Fiocruz, 2003. p. 15-38.

CARTA DE OTTAWA. Disponível em: <www.universidadesaudavel.com.br>. Acesso em: 23 jun. 2005.

CARVALHO, S.R. Saúde Coletiva e Promoção da Saúde: sujeito e mudança. São Paulo: Hucitec, 2005.

CZERESNIA, D. O conceito de saúde e a diferença entre prevenção e promoção. In: CZERESNIA, D.; FREITAS, C.M. (Org.). Promoção da Saúde: conceitos, reflexões, tendências. Rio de Janeiro: Fiocruz, 2003.

DUARTE, B.Z; SILVA, V.P. Porção Insular do Município de Belém: uma análise censitária nas ilhas Jutuba, Urubuoca e Nova de 2008 a 2010. Trabalho de Conclusão de Curso de Graduação. Belém: Instituto Federal de Educação, Ciência e Tecnologia do Pará, 2011. 
HELLER, L.; NASCIMENTO, N.O. Pesquisa e desenvolvimento na área de saneamento no Brasil: necessidades e tendências. Revista de Engenharia Sanitária e Ambiental, v. 10, n. 1, p. 24-35, 2005.

INSTITUTO BRASILEIRO DE GEOGRAFIA E ESTATÍSTICA. Pesquisa Nacional de Saneamento Básico. Disponível em: <http://www.ibge.gov.br/ home/estatistica/populacao/condicaodevida/pnsb2008/PNSB_2008.pdf>. Acesso em: 14 abr. 2010a.

INSTITUTO BRASILEIRO DE GEOGRAFIA E ESTATÍSTICA. Censo 2010. Disponível em: <http://www.ibge.gov.br/cidadesat/topwindow.htm?1>. Acesso em: 14 abr. 2010b.

LEFÈVRE, F; LEFÈVRE, A.M.C. Promoção de Saúde: a negação da negação. Rio de Janeiro: Vieira \& Lent, 2004.

SILVA, H.P. A saúde humana e a Amazônia no século XXI: reflexões sobre os objetivos do milênio. Novos Cadernos NAEA, Belém, v. 9, n. 1, p. 77-94, 2006.

SISTEMA NACIONAL DE INFORMAÇÕES SOBRE SANEAMENTOSNIS. < http:/ /www.snis.gov.br/PaginaCarrega.php?EWRErterterTERTer=6>. Acesso em: 14 abr. 2011.

SOUZA, C.M.N. A relação saneamento-saúde-ambiente: um estudo sobre discursos setoriais na perspectiva da Promoção da Saúde e da prevenção de doenças. 2007. Tese (Doutorado) - Escola Nacional de Saúde Pública Sérgio Arouca, Fundação Oswaldo Cruz, Rio de Janeiro, 2007.

SOUZA, C.M.N.; FREITAS, C.M.; MORAES, L.R.S. Discursos sobre a relação saneamento-saúde-ambiente na legislação: uma análise de conceitos e diretrizes. Revista de Engenharia Sanitária e Ambiental, Rio de Janeiro, v. 12, n. 4, p. 371-379, 2007.

SOUZA, C.M.N.; FREITAS, C.M. O saneamento na ótica dos profissionais de saneamento-saúde-ambiente: promoção da saúde ou prevenção de doenças? Revista de Engenharia Sanitária e Ambiental, Rio de Janeiro, v. 13, n. 1, p. 46-53, 2008.

Discursos de usuários sobre uma intervenção em saneamento: uma análise na ótica da Promoção da Saúde da prevenção de doenças. Revista de Engenharia Sanitária e Ambiental, Rio de Janeiro, v. 14, n. 1, p. 59-68, 2009. 
SOUZA, C.M.N.; FREITAS, C.M. A produção científica sobre saneamento: uma análise na perspectiva da promoção da saúde e da prevenção de doenças. Revista de Engenharia Sanitária e Ambiental, Rio de Janeiro, v. 15, n.1, p. 65-74, 2010.

STATCHENKO, S.; JENICECK, M. Conceptual differences between prevention and health promotion: research implications for community health programs. Canadian Journal of Public Health, v. 81, p. 53-59, 1990.

WALTNER-TOWES, D. The end of medicine: the beginning of health. Futures, v. 32, p. 655-667, 2000. 